\title{
Contribuições de Paulo Freire para uma compreensão do trabalho com a Modelagem na Formação Inicial de Professores de Matemática ${ }^{1}$
}

\author{
Ana Paula dos Santos Malheiros \\ Professora, IBILCE - UNESP - São José do Rio Preto, SP \\ e PPGEM - UNESP - Rio Claro, SP \\ paulam@ibilce.unesp.br
}

\begin{abstract}
Resumo
A Modelagem é vista como um dos caminhos para os processos de ensino e aprendizagem de Matemática nas escolas de Educação Básica. Diante desse cenário, estudos apontam a importância, para o futuro professor de Matemática, do contato com a Modelagem em sua formação inicial. Nesse sentido, esse artigo $^{2}$ tem como objetivo apresentar contribuições de parte da obra de Paulo Freire para uma compreensão do trabalho com a Modelagem na formação inicial de professores de Matemática. A pesquisa foi realizada a partir de uma abordagem qualitativa e os dados foram coletados em uma disciplina obrigatória do curso de Licenciatura. Nesse cenário, identifiquei como o trabalho com a Modelagem nos cursos de Licenciatura em Matemática suscita a insegurança, mas também pode contribuir para o exercício da autonomia dos futuros professores de Matemática. Ainda destaco que o desenvolvimento de Projetos de Modelagem, nesse contexto, pode contribuir para reflexões sobre os processos de ensino e aprendizagem de Matemática, considerando questões como criticidade, o papel da Matemática na sociedade, ser participante ativo da construção do conhecimento, exercício da cidadania e autonomia na Educação Básica.
\end{abstract}

Palavras-chave: Educação Matemática. Autonomia. Licenciatura em Matemática. Diálogo. Formação de Professores.

\section{Paulo Freire's Contributions to an Understanding of work with Modeling in Mathematics Teachers Initial Formation}

\begin{abstract}
Modeling is seen as one of the paths to follow for Mathematics teaching and learning in basic education. Studies have shown the importance of future Mathematics teachers having contact with modeling at their initial teacher education. This article aims at presenting the contributions of a part of Brazilian educator Paulo Freire's work to an understanding of work with modeling in Mathematics Teacher initial formation. This piece of research was carried out with a qualitative approach, and data were collected in a core course of the undergraduate program in Mathematics. Results have shown how working with modeling in a Mathematics teacher education program gives rise to insecurity, but can also contribute to future Mathematics teachers' exercise of autonomy. Additionally, I emphasize that the development of modeling projects, in this context, might contribute to reflection on Mathematics teaching and learning processes, considering issues such as critical thinking, the role of Mathematics in society, students' active participation in knowledge construction, and the exercise of citizenship and autonomy in basic education.
\end{abstract}

Keywords: Mathematics Education. Autonomy. Mathematics Teacher Education Program. Dialogue. Teacher Education.

\section{Introdução}

\footnotetext{
${ }^{1}$ Boletim Gepem (Online) ISSN: 2176-2988 | n. 64 - Jan./Jun. 2014 (texto em diagramação).

${ }^{2}$ Embora não sejam responsáveis pelo conteúdo desse artigo, agradeço aos membros do GPIMEM pelas críticas e sugestões às versões iniciais do texto, assim como a Angélica Karim Garcia Simão pelas contribuições.
} 
A Modelagem permeia o cenário das pesquisas nacionais em Educação Matemática desde os anos 1970 e investigações na área têm crescido nos últimos anos. Entretanto, resultados sugerem que ela ainda não chegou, de fato, às salas de aula de Matemática (OLIVEIRA, 2010). Na literatura específica sobre o tema, não há uma única definição de Modelagem, mas as concepções apresentadas apontam convergências. Nesse artigo, ela é compreendida como uma abordagem pedagógica, na qual alunos, partindo de um tema ou problema de interesse deles, utilizam a Matemática para investigá-lo ou resolvê-lo, tendo o professor como orientador durante todo o processo (MALHEIROS, 2008). Nessa direção, ela pode ser vista como caminho para o “fazer" Matemática em sala de aula, pois a partir de observações da realidade e de questionamentos, discussões e investigações, os estudantes escolhem um tema de seu interesse e, ao fazerem Modelagem, se deparam com problemas que podem modificar as ações na sala de aula, além da forma como se compreende o mundo. Tal ideia se aproxima daquilo que Freire (2005) denomina "leitura de mundo".

Independente da perspectiva de Modelagem adotada, pesquisas como a de Silveira e Caldeira (2012) evidenciam as resistências e obstáculos acerca de sua presença nas aulas de Matemática. Nesse sentido, são consideradas importantes as iniciativas do trabalho com Modelagem na formação inicial do professor de Matemática (BARBOSA, 2001; 2004; OLIVEIRA, 2007). Diante desse cenário foi realizada uma pesquisa que teve como contexto a disciplina "Metodologias de Ensino de Matemática e Estágio Supervisionado I"3, e, nesse artigo, apresento como resultado da mesma uma compreensão do trabalho com a Modelagem na formação inicial de professores de Matemática, a partir das contribuições de parte da obra de Paulo Freire.

\section{Modelagem e Formação de Professores}

Pesquisas sobre a formação do professor de Matemática têm sido desenvolvidas relacionando-a com a Modelagem. Nas investigações acerca da formação inicial, encontramos autores que, por um lado, reforçam a ideia de que é preciso que a Modelagem seja incorporada, na prática, nos cursos de Licenciatura em Matemática. É necessário ler e discutir sobre Modelagem, mas não é suficiente. É preciso "fazer" Modelagem nas diferentes disciplinas presentes no currículo (BARBOSA, 2001). Com

\footnotetext{
${ }^{3}$ Doravante tal disciplina será denominada "Estágio I", com intuito de evitar repetições.
} 
isso, os pesquisadores acreditam que a Modelagem poderá ser incorporada na prática dos futuros professores.

Por outro lado, encontramos na literatura (BARBOSA, 2001, 2004; SILVEIRA; CALDEIRA, 2012) relatos sobre a dificuldade de se empregar a Modelagem nas aulas de Matemática da educação básica. Os argumentos apresentados pelos professores são inúmeros, entre eles os programas curriculares pré-estruturados, a resistência dos pais, a burocracia educacional, a falta de preparo docente e a insegurança ${ }^{4}$ e resistência dos alunos que "[...] não acostumados ao processo, podem se sentir impotentes/incapazes frente às exigências de uma aula do tipo" (BASSANEZZI, 1999, p.15).

Parte dos resultados apresentados por Barbosa (2004) e Bassanezzi (1999) também são evidenciados em Silveira e Caldeira (2012) alguns anos mais tarde, o que evidencia que esse quadro ainda se perpetua nas aulas de Matemática. Para eles, as dificuldades ao se trabalhar com a Modelagem perpassam quase

[...] todos os âmbitos constituintes do trabalho docente: preparação das aulas; relação com os alunos; relação com a família dos alunos; estrutura administrativa e pedagógica das escolas; currículo e questões pessoais, como por exemplo, a insegurança diante do novo (SILVEIRA; CALDEIRA, 2012, p.1043)

Porém, de uma maneira geral, quando os professores se deparam com a Modelagem e suas possibilidades, mostram-se receptivos à proposta. Ademais, Silveira e Caldeira (2012) concluem que seus estudos apontam para indagações acerca de como é possível a incorporação e manutenção da Modelagem nas salas de aulas de Matemática.

\section{Modelagem e alguns Pressupostos Freireanos}

A Modelagem é considerada uma das abordagens pedagógicas para os processos de ensino e aprendizagem da Matemática (BRASIL, 2006) mencionadas nos documentos oficiais. Entretanto, muitos professores e alunos não se sentem confortáveis ao trabalhar com ela em sala de aula. Isso vai ao encontro do que Paulo Freire menciona a respeito da ruptura de um modelo educacional existente, a educação bancária (FREIRE, 2005). Para o autor, formar um indivíduo é muito mais do que puramente treiná-lo, por meio da transmissão, no desempenho de destrezas, pois, ensinar, para ele, exige que o educando se aproprie do significado do conteúdo que está sendo ensinado.

\footnotetext{
${ }^{4}$ Nesse artigo, insegurança está sendo entendida com o receio dos professores e futuros professores diante de questões novas para eles.
} 
Além disso, para que exista a mudança de paradigma nos atos de ensinar e, consequentemente, aprender, Freire (2005) prega uma educação dialógica, feita em conjunto, colaborativamente, com vistas a reforçar a capacidade crítica do educando. Para ele, “[...] a educação autêntica, [...] não se faz de A para B ou de A sobre B, mas de A com B, mediatizados pelo mundo" (ibidem, p.97, grifo do autor). Esse modelo de educação proposto é contrário a uma educação baseada em memorizações, que lhes tira a liberdade de criar, explorar, investigar e construir o conhecimento, e contribui para que o estudante não desenvolva a autonomia, entendida aqui como um processo de decisão e humanização construído a partir das experiências vividas e compartilhadas. Ou seja,

\begin{abstract}
Ninguém é autônomo primeiro para depois decidir. A autonomia vai se constituindo na experiência de várias, inúmeras decisões, que vão sendo tomadas. [...] A gente vai amadurecendo todo dia, ou não. A autonomia, enquanto amadurecimento do ser para si, é processo, é vir a ser. Não ocorre em data marcada. É neste sentido que uma pedagogia da autonomia tem de estar centrada em experiências estimuladoras da decisão e da responsabilidade, vale dizer, em experiências respeitosas da liberdade (FREIRE, 2001, p.105).
\end{abstract}

Nessa direção, para Freire (2011), a educação é uma especificidade humana e um ato de intervenção no mundo e deve ser comprometida com a cidadania. $\mathrm{O}$ autor afirma que a educação, sozinha, não transforma o mundo, mas que pode contribuir para essa transformação. Para tanto, destaca a importância dos educandos aprenderem a perguntar, indo contra a cultura do silêncio. Segundo ele, na maioria das vezes, os professores apresentam respostas em sala de aula sem que nenhuma pergunta tivesse sido feita, acarretando, com isso, a "castração da curiosidade" (FREIRE; FAUNDEZ, 2011). A maior parte das escolas, entretanto, recusa ou burocratiza o ato de perguntar, tolhendo o aluno de buscar o saber, pois “[...] a pedagogia da resposta é uma pedagogia da adaptação e não da criatividade. Não estimula o risco de invenção e da reinvenção" (ibidem, p.75). A cultura da pedagogia da resposta, autoritária, em detrimento à pedagogia da pergunta, é um dos entraves para que consigamos, por meio da educação, ter estudantes autônomos, críticos e reflexivos.

Considerando parte da obra de Paulo Freire, encontramos convergências entre ela e a perspectiva de Modelagem defendida nesse artigo (MALHEIROS, 2012; 2013). Na Modelagem, elementos como a criticidade, o diálogo, a investigação, a problematização e a autonomia são fundamentais. Ao eleger um assunto para explorar, os estudantes devem pesquisar, fazer perguntas, conjecturas e delimitar o foco de sua investigação, 
para, então, iniciar a coleta de dados e dar continuidade ao processo de Modelagem. Esse exercício, que exige autonomia, muitas vezes é novo para os alunos, acostumados à cultura do silêncio e à pedagogia da resposta. Sendo assim, faz-se necessário também que futuros professores de Matemática tenham vivências acerca da Modelagem em sala de aula, para que possam compreender suas possibilidades enquanto abordagem metodológica, além de discutir sobre ela, considerando sua futura prática em sala de aula.

\section{A Metodologia, a Pesquisa e seu Cenário}

Diante do objetivo e do contexto no qual essa pesquisa foi desenvolvida, a metodologia adotada foi qualitativa, visto que uma das principais características dessa abordagem é seu aspecto interpretativo (ALVES-MAZZOTTI, 2001). O pesquisador, ao utilizar esta abordagem, tem como objetivo compreender de que forma as pessoas, em um contexto particular, pensam e agem.

Nesse sentido, foram utilizados como procedimentos metodológicos a observação participante, tanto nos momentos em que os Projetos de Modelagem estavam em desenvolvimento em sala de aula, como na apresentação dos mesmos para os colegas e também nos debates que surgiram em momentos específicos nas aulas. Ainda, as versões dos Projetos elaborados e as notas de aula também se tornaram registros importantes. Alguns momentos das aulas, nos quais os projetos ou questões relacionadas a eles eram debatidas, foram audiogravados e, posteriormente, transcritos. A partir da coleta desses dados, foram realizadas triangulações (ARAÚJO; BORBA, 2004) buscando compreender como se deu o processo de elaboração de Projetos de Modelagem, além de identificar as possíveis contribuições dessa ação na formação dos futuros professores de Matemática.

A disciplina, cenário da pesquisa, tem como principal objetivo qualificar os licenciandos para o trabalho docente no Ensino Fundamental e Médio. Nela, os alunos conhecem as diferentes tendências em Educação Matemática e também fazem um estágio de observação de 60 horas nas escolas de Educação Básica. A turma da pesquisa em questão tinha 12 alunos, estudantes do período integral do curso de Licenciatura em Matemática.

Como parte das atividades da disciplina, os estudantes, em grupos, deveriam eleger um tema de interesse para o desenvolvimento de um Projeto de Modelagem (MALHEIROS, 2008). Versões desses projetos eram entregues em datas pré- 
estabelecidas, mas outras também poderiam ser entregues a qualquer momento, a critério dos grupos. Reuniões extra sala de aula também poderiam ser agendadas para a orientação do projeto, assim como alguns momentos nas aulas eram destinados para o debate sobre o desenvolvimento dos mesmos. Ao final do semestre, os alunos realizaram a apresentação dos projetos, com intuito de socializar o trabalho desenvolvido. Posteriormente houve discussões sobre as dificuldades encontradas, as possibilidades de levar a Modelagem para a sala de aula, dentre outras questões.

\section{"Mas, o que é para fazer?"}

Nesse artigo, não vou focar nos Projetos de Modelagem propriamente ditos e sim no caminhar de seu desenvolvimento, com vistas a compreender o fazer Modelagem na formação inicial de professores de Matemática. Anterior a proposta da elaboração dos Projetos de Modelagem, foi apresentado o que era a Modelagem, no contexto da Educação Matemática e leituras sobre o tema foram agendadas para as aulas seguintes. Na sequência, foi solicitado que os alunos se dividissem em grupos de 3 a 4 integrantes e que escolhessem um tema qualquer, de seu interesse, para investigar. Depois de realizada a explanação, a pergunta imediata de uma das alunas, foi "Mas, o que é para fazer?". Foi elaborado um novo encaminhamento, reafirmando que eles deveriam desenvolver um Projeto de Modelagem e que, para tanto, era necessário, a priori, que um tema de interesse do grupo fosse eleito e que eles justificassem a escolha do mesmo.

$\mathrm{Na}$ aula seguinte, nenhum grupo entregou o tema com a respectiva justificativa, alegando que não haviam compreendido o que deveria ser feito. Nesse episódio temos a questão da cultura da resposta (FREIRE; FAUDEZ, 2011) em destaque. Os alunos, desacostumados a ter que escolher algo em sala de aula, visto que trabalham a partir de ordens efetivas do que tem que ser feito, não sabiam o que deveria ser realizado.

Diante da situação, expliquei novamente o que era Modelagem, dei exemplos de temas e possibilidades de desdobramentos dos mesmos, evidenciei a importância daquele momento para os alunos, futuros professores de Matemática, no sentido de eles estarem diante de aspectos já discutidos em sala de aula, a saber, a problematização, a resolução de problemas e a formação de alunos críticos e reflexivos. Os alunos pareciam ter entendido a proposta de trabalho, embora estivesse nítida a insegurança de alguns. 
$\mathrm{Na}$ aula seguinte os grupos de estudantes entregaram os temas e a justificativa dos mesmos. Foram feitas considerações e apresentados encaminhamentos, a maior parte na forma de questionamentos, os quais foram entregues na aula subsequente, para que os estudantes pudessem dar continuidade ao processo.

Após algumas aulas sem qualquer questionamento por parte dos alunos com relação ao Projeto de Modelagem, resolvi perguntar como estava o desenvolvimento do mesmo. Para meu espanto, os alunos afirmaram que pouco havia sido desenvolvido, visto que eles ainda estavam com dificuldades em compreender o que deveriam fazer. Diante de tal resposta, discuti com eles as dificuldades que estavam encontrando. Ficou combinado que na aula seguinte eles entregariam uma nova versão, com as informações que encontraram, com o foco que dariam na temática escolhida e com as dúvidas que eles tinham por escrito.

Conforme combinado, os alunos entregaram uma nova versão do Projeto e, a partir de então o diálogo entre os alunos e eu foi estabelecido efetivamente, na perspectiva que Freire (2005) evidencia. O diálogo era com os alunos. Entretanto, a resistência e as dificuldades apresentadas por eles foram surpreendentes. Durante o início do processo, principalmente, perguntas como “o que é para fazer agora?" e expressões como "isso é muito difícil”, dentre outras, foram frequentes.

Versões foram elaboradas pelos estudantes, até o final do Projeto. Eu havia solicitado três obrigatórias e todos entregaram outras além dessas, sendo que um dos grupos entregou seis versões, antes da final. Todos os alunos concluíram a elaboração de seus Projetos de Modelagem, apresentaram para os demais e entregaram a versão final, na qual incorporaram algumas sugestões apresentadas pelo restante da turma.

Após todos os grupos apresentarem seus projetos, propus uma dinâmica de avaliação, na qual os futuros professores deveriam escrever sobre a experiência de elaboração do Projeto de Modelagem, considerando suas visões enquanto aluno e também como futuro professor. A seguir, alguns trechos da avaliação dos alunos:

"No começo foi muito difícil, talvez pela falta de hábito [...] mas depois, percebemos como era bom poder gerenciar nossa aprendizagem. Isso foi o mais legal" (Pedro 5 ).

"Fazer Modelagem para mim foi uma experiência muito boa, desafiadora mesmo. Me senti no controle das decisões, aprendi muito, junto com meus colegas, sob a orientação da professora. [...] Mas, não me sinto a vontade para levar essa proposta para a sala de aula. Não desse jeito" (Samara).

\footnotetext{
${ }^{5}$ Os nomes utilizados são fictícios.
} 
"Penso que levar a Modelagem para a sala de aula não é fácil, considerando como fizemos, nós totalmente livres e também as escolas de hoje. Mas, acho que dá para adaptar e levar de algum jeito, sim.” (Luciano)

Após a leitura das avaliações, sessões de debate foram realizadas em sala de aula, com intuito de compartilhar as impressões da elaboração dos Projetos de Modelagem e fomentar a discussão, considerando principalmente as futuras atividades docentes dos licenciandos. Surgiram questões como: a importância da criticidade; o papel da Matemática na sociedade; o aluno como sujeito ativo na construção do conhecimento matemático e sua mudança de postura nas ações em sala de aula (de um sujeito passivo para ativo); a importância do exercício da cidadania e da autonomia dentro da sala de aula. Tais temas foram debatidos e as atividades de Modelagem foram evidenciadas pelos estudantes como um caminho para leva-los e explora-los nas aulas de Matemática da Educação Básica.

Os futuros professores, no geral, gostaram da experiência vivenciada, porém se sentiram inseguros, principalmente no início e poucos afirmaram estar confortáveis para trabalhar com a Modelagem, na perspectiva utilizada por $\operatorname{mim}^{6}$. Afirmaram que eu deveria começar com "uma Modelagem mais fechadinha" (Luciano) e, conforme fossem adquirindo confiança, poderiam dar maior abertura nas atividades.

Ainda relataram, a partir do que observaram nas escolas públicas do estado de São Paulo, que só veem a Modelagem como possibilidade de abordagem pedagógica em uma perspectiva na qual o professor escolhe o tema a ser trabalhado, para que um determinado conteúdo seja abordado. Tal consideração se baseia no fato de que, nas escolas observadas, a preocupação dos professores, no geral, é com o desempenho dos estudantes nas avaliações em larga escala. Essas avaliações não são elaboradas por eles e sim pelo Estado, e acabam por ranquear as escolas e gerar prêmios financeiros para todos os trabalhadores das instituições de ensino.

\section{Superando a Insegurança e Exercitando a Autonomia}

Diante do que foi apresentado na seção anterior, podemos perceber que os futuros professores de Matemática, acostumados a uma educação bancária (FREIRE, 2005) e à pedagogia da resposta (FREIRE; FAUDEZ, 2011), sentiram-se inseguros ao trabalhar com a Modelagem da maneira como lhes foi sugerido. Eles, principalmente no

\footnotetext{
${ }^{6}$ Dois alunos dessa turma incorporaram a Modelagem em suas atividades de regência, na disciplina "Metodologias de Ensino de Matemática e Estágio Supervisionado II”, no ano seguinte.
} 
início, necessitavam de um roteiro, de que eu lhes dissesse exatamente o que era para ser feito. Ainda, embora critiquem as aulas de transmissão e reprodução, não souberam direito como lidar quando tiveram alguma liberdade em sala de aula. Desse modo,

[...] um dos problemas mais sérios é como enfrentar uma poderosa e antiga tradição de transferência de conhecimento. Até os estudantes têm dificuldade em entender um professor que não faz transferência de conhecimento. Os estudantes não acreditam num professor libertador que não lhes empurre o conhecimento goela abaixo (FREIRE; SHOR, 2011, p. 28).

Para superar tal situação, o diálogo entre os alunos e eu foi fundamental, pois foi na relação dialógica (FREIRE, 2005) que a confiança dos alunos para o desenvolvimento do Projeto de Modelagem foi sendo fortalecida. Desse modo, ao se trabalhar com Modelagem na perspectiva adotada, a criticidade, o diálogo, a investigação, a problematização e a autonomia são imprescindíveis por parte dos estudantes. Quando elegem um assunto para explorar, os estudantes devem pesquisar, fazer perguntas, dialogar, conjecturar e delimitar o foco de sua investigação, para, então, iniciar a coleta de dados e dar continuidade ao processo de Modelagem. Assim, o papel do professor é de mediador durante todo o processo e, para tanto, o diálogo é fundamental. A questão da insegurança dos alunos ao fazer Modelagem, na formação inicial, também é evidenciada por Oliveira (2007), dentre outros autores, que destaca que as ações não previsíveis, comuns quando se faz Modelagem, são vistas como obstáculos pelos futuros professores.

Outro aspecto que pôde ser identificado nas falas dos estudantes é a pouca autonomia dos mesmos. Isso pode estar relacionado ao modelo de educação que a maior parte vivencia desde a escola básica, a educação bancária (FREIRE, 2005). Sobre tal fato, Freire (2011, p. 105) afirma que a autonomia não se adquire de uma hora para outra e que deve "[...] estar centrada em experiências estimuladoras da decisão e da responsabilidade, vale dizer, em experiências respeitosas da liberdade".

Nesse sentido, é possível inferir que a Modelagem pode contribuir para o desenvolvimento e exercício da autonomia dos alunos, mas apenas uma atividade de Modelagem, ao longo de todo um curso de formação de professores, é pouco para isso. Seria preciso outras vivências para que eles, pouco a pouco, se tornassem mais autônomos. Isso vai ao encontro do que Barbosa $(2001 ; 2004)$ apresenta como 
importante na formação de professores, quando se leva em consideração a Modelagem. É preciso que os futuros professores tenham experiências como alunos e também como professores. São momentos distintos que podem ter implicações significativas para a futura prática docente.

Entretanto, a avaliação final dos estudantes foi positiva, no sentido de sentiremse mais confiantes e capazes de elaborar atividades como a proposta. Descobriram-se participantes efetivos do processo e a autonomia deles foi exercitada por meio do diálogo com a professora e também com os colegas.

De todo modo, parte dos estudantes ainda se sente insegura para levar a Modelagem, da maneira como foi proposta, para as aulas de Matemática. Para eles, seria preciso mais experiências dessa natureza para que pudessem se sentir mais confiantes. Ainda, a vivência dos estudantes possibilitou reflexões profundas sobre os processos de ensino e aprendizagem de Matemática, considerando questões como criticidade, o papel da Matemática na sociedade, ser participante ativo da construção do conhecimento, exercício da cidadania e autonomia.

Outro fator, mencionado pelos estudantes, em mais de um momento, diz respeito às escolas e às dinâmicas de avaliação que elas estão sendo submetidas atualmente. Silveira e Caldeira (2012) destacam tal fato e afirmam que essas avaliações, que acabam por ranquear as escolas públicas, podem ser um dos empecilhos para que a Modelagem chegue de fato às salas de aula.

\section{Considerações Finais}

Nesse texto discuti sobre como o trabalho com a Modelagem nos cursos de Licenciatura em Matemática pode suscitar a insegurança diante do novo, mas que, por meio do diálogo, também pode contribuir para o exercício da autonomia, na perspectiva de Paulo Freire, dos futuros professores de Matemática. Eles foram convidados a elaborar Projetos de Modelagem, atividade desconhecida deles até então, e a insegurança se fez explícita, corroborando outras pesquisas presentes na literatura em Modelagem nacional. O medo do novo, devido à falta de hábito em desenvolver atividades nas quais eles estão no comando, fez com que os estudantes tivessem dificuldades no início do desenvolvimento da atividade.

Porém, a partir da análise dos dados, é possível afirmar que os estudantes superaram a insegurança e exercitaram a autonomia na elaboração dos Projetos de Modelagem. Ainda, as discussões que aconteceram durante a disciplina sobre o papel 
dos estudantes e professores frente às atividades dessa natureza, além da importância da criticidade, autonomia, o papel da Matemática na sociedade e do exercício da cidadania nas aulas de Matemática foram importantes para a formação desses futuros professores.

Sendo assim, esse pode ser considerado um primeiro passo para que mudanças na prática dos futuros professores possam ocorrer efetivamente. Entretanto, no caso específico da Modelagem, é preciso que outras ações sejam desenvolvidas ao longo de todo o curso de formação.

Nesse sentido, uma única atividade de Modelagem, em uma única disciplina, como no caso dessa pesquisa, pode contribuir em vários aspectos para a formação dos futuros professores de Matemática, mas é preciso que mais ações sejam desenvolvidas, para que essa abordagem pedagógica possa chegar às aulas de Matemática. No entanto, entendo que só ações em cursos de formação não bastam. É necessário também que as políticas públicas elaboradas para as escolas brasileiras contribuam para que os professores possam, de fato, modificar as aulas de Matemática, no sentido de tornar efetivamente os alunos sujeitos de sua aprendizagem, críticos, reflexivos e capazes de exercer a cidadania.

\section{Referências}

ALVES-MAZZOTTI, A. O Método nas Ciências Sociais. In: ALVES-MAZZOTTI, A.J.; GEWAMDSZNADJDER, F. O método nas ciências naturais e sociais: pesquisa quantitativa e qualitativa. $2^{\mathrm{a}}$ reimpressão da $2^{\mathrm{a}}$ edição. São Paulo: Pioneira, 2001. p.107188.

ARAÚJO, J. L.; BORBA, M. C. Construindo Pesquisas Coletivamente em Educação Matemática. In: BORBA, M. C.; ARAUJO, J. L. (Org.). Pesquisa Qualitativa em Educação Matemática. Belo Horizonte: Autêntica, 2004. p.25-45.

BARBOSA, J. C. As Relações dos Professores com a Modelagem Matemática. Anais do VIII Encontro Nacional de Educação Matemática. Anais... ENEM. Recife, PE. 2004.

BARBOSA, J. C. Modelagem Matemática: Concepções e Experiências de Futuros Professores. 2001. Tese (Doutorado em Educação Matemática) - Instituto de Geociências e Ciências Exatas, Universidade Estadual Paulista, Rio Claro, 2001.

BASSANEZZI, R. C. Modelagem Matemática: uma disciplina emergente nos programas de formação de professores. 1999. Disponível em [http://www.ime.unicamp.br/ biomat/bio9art_1.pdf], Acesso em 26 de outubro de 2010.

BRASIL. Secretaria de Educação Média e Tecnológica. Orientações Curriculares para o Ensino Médio, v. 2. Ciências da Natureza, Matemática e suas Tecnologias. Brasília: Ministério da Educação, 2006. 
FREIRE, P. Pedagogia da Autonomia: saberes necessários à prática educativa. São Paulo: Paz e Terra, 2011.

FREIRE, P. Pedagogia do Oprimido. 49a Reimpressão. Rio de Janeiro: Paz e Terra, 2005.

FREIRE, P.; FAUNDEZ, A. Por uma Pedagogia da Pergunta. $7^{\text {a }}$ Edição Rev. Ampliada. Rio de Janeiro: Paz e Terra, 2011.

FREIRE, P.; SHOR, I. Medo e Ousadia: o cotidiano do professor. 13ª Edição. Rio de Janeiro: Paz e Terra, 2011.

MALHEIROS, A. P. S. Diálogos entre Modelagem e Paulo Freire: possibilidades para a sala de aula. In: Conferência Nacional de Modelagem em Educação Matemática, 8 (VIII CNMEM). 2013. Santa Maria, RS. Anais... Santa Maria: UNIFRA, 2013. V. único.

MALHEIROS, A. P. S. Delineando Convergências entre Investigação Temática e Modelagem Matemática. In: Seminário Internacional de Pesquisas em Educação Matemática, 5 (V SIPEM). 2012. Petrópolis, RJ. Anais... Rio de Janeiro: Sociedade Brasileira de Educação Matemática, 2012. V. único

MALHEIROS, A. P. S. Educação Matemática online: a elaboração de projetos de Modelagem Matemática. 2008. Tese (Doutorado em Educação Matemática) - Instituto de Geociências e Ciências Exatas (IGCE), Universidade Estadual Paulista (UNESP), Rio Claro - SP, 2008.

OLIVEIRA, A. M. P. Modelagem Matemática e as tensões nos discursos dos professores. 2010. Tese (Doutorado em Ensino, Filosofia e História das Ciências) Universidade Federal da Bahia, Instituto de Física. Universidade Estadual de Feira de Santana. Salvador, 2010.

OLIVEIRA, A. M. P. As análises dos futuros professores sobre suas primeiras experiências com Modelagem Matemática. In: BARBOSA, J.C.; CALDEIRA, A.D.; ARAÚJO, J.L. Modelagem Matemática na Educação Matemática Brasileira: Pesquisas e Práticas Educacionais. Recife: SBEM, 2007. p. 215-232. (Biblioteca do Educador Matemático). V.3.

SILVEIRA, E.; CALDEIRA, A. D. Modelagem na sala de aula: resistências e obstáculos. Bolema. Rio Claro, SP. V. 26, n 43, pp. 249-275. Ago. 2012. 